\title{
Modern distance education theory and practice innovation under the lifelong education system
}

\author{
Chenan Peng Duan \\ Guangdong University of Technology, Guangdong Guangzhou 510006
}

\begin{abstract}
Summary : Modern distance education models are valued for their advantages ., But distance learning has also revealed many problems as it grows. . How to: in the process of establishing and perfecting a lifelong education system, Innovation in theory and practice for modern distance education, This is an urgent problem to solve now . to this, Opportunities and challenges under the lifelong education system based on modern distance education, Strengthening communication and interaction between teachers and students in distance education , Clean network, Create good learning environment, Establish a sound certification and evaluation mechanism for teachers, public -private education institutions open deep cooperation, promoting the life-long education system under modern distance teaching education Theory and Practice Innovation .
\end{abstract}

Keywords: Lifelong Education ; Modern Distance education ; Opportunities and challenges ; Countermeasures

from century Date, Lifelong education as an international trend Flow, in countries around the world have evolved from concept to concrete national strategy and reform measures, China no exception . lifelong education and modern distance education There is an intrinsic connection, This connection makes modern distance education and lifelong education system interaction, Mutual impact and mutual promotion .

one, Background to the formation and development of lifelong education systems

Lifelong Education, As the name implies, is a lifelong learning, can accept for life Education Trends , dedicated to human development, under the influence of this trend of thought, each educational institutions and social groups provide learning and education for social groups Opportunity The Education network that is formed by the, is the lifelong education system .

in 1965 Year, Paul - Langrand in UNESCO third Session of Adult Education Commission International Conference on Adult Education for the first time "'" the concept of lifelong learning . This philosophy of lifelong education covers the following: knowledge, Culture, learning activities such as skills, differs from traditional school education ,It The timeliness of the is not limited to the school stage, but it 's a lifetime spread. , Education no longer exists only in major schools , It extends to the entire human community .. is Because of these advantages, lifetime education from century 60 years, Its development is like a torrent, spreads around the world , people praise their ' is comparable to the Copernican doctrine . Many countries now take lifelong education concept as Guiding principles of education reform in the century and actively engage inThe practice of building lifelong education system .

Different people have different understandings of the concept and connotation of lifelong education , but is no matter how you understand its concepts and connotations, no question about, Lifelong teaching The establishment of education is an Educational Progress for both individuals and society One manifestation, General Human Development, Quality Improvement, increased skills and abilities Strong as well as social harmony and progress all play a very important role . on the one hand, evolving modern society and modern

\footnotetext{
Copyright (C)

This is an open-access article distributed under the terms of the Creative Commons Attribution Unported License

(http://creativecommons.org/licenses/by-nc/4.0/), which permits unrestricted use, distribution, and reproduction in any medium, provided the original work is properly cited.

enterprise demand for highly qualified personnel rise capabilities increasingly become a focus of business ,
} 
for social groups Body ,How to improve the viability of your own market economy, is required Realistic issues to resolve ; in the Lifetime education system, Learn all kinds of knowledge ,Technology To enrich individual mental world, Improve survivability, Enhance personal strength Concept can effectively improve the quality of people in social groups, in original knowledge, Technology on the basis of further learning, developing itself, adapt to The Times . another aspect, Establishment and improvement of lifelong education system, is also a person's overall development must require . look at the past and last, human beings learn from the ancient apes, Practice , in Learn lessons from failure, get joy in Success, until modern, Development level compared to Previous, Dramatic Change, people starting from appearance, learning and sending Show is the inner requirement of the person's, , in modern times is no exception . on city field economic wave, human survival and development need people to keep learning status ,The development of lifelong education system is undoubtedly in conformity with human self-development. You need to to .

two , Modern distance education faced with the system of lifelong education Opportunities and challenges to use computer technology and digital multimedia technology as a learning tool for Modern Distance education , has become a new situation in modern distance education, In recent years The is fast growing globally .. Modern distance education break time and null restrictions, is an important teaching tool for building a lifelong education system . Modern far Education helps integrate a large number of teaching resources, provides diversity for different groups of To, flexible, Rich Educational services . in the establishment and development of the lifelong education system show, Modern distance education is an important part that cannot be neglected, Lifelong teaching The education system in the development of modern distance learning opportunities in the same time , also give it to challenge .

1. Development Opportunitiesin the Lifetime education system, In addition to the students in major institutions Group, get a lot of participation in learning activities to develop your strength and survival opportunity for Ability, But for this group of social groups, one not allowed The problem with ignoring them is that they don't have as much school students as they do on campus . the time and place of learning . the Primary task for students at school is to learn, their time can be used as a learning, and taught by specialized teachers, has special places for students to learn or query data, These are for social groups A tough question, Most of these people are already at work, Their main To work instead of learning, in other words, under Limited time, They can be allocated less time to study, Although the Lifetime education system's establish opportunities for learning and certain places of learning for these social groups , But they don't have enough time and energy to do the same as school students. Learning activities, therefore, Traditional classroom instruction is not quite applicable to these societies crowd.

Modern distance education based on the development of modern information technology, To become an essential part of the lifelong education system . Modern distance education and tradition Different class instruction system , under Network technology and modern information technology now on- behalf Distance education, does not require people to do learning activities in specialized places, only to have a computer, at home You can also participate in distance learning through the Internet ;People You can choose what you want to learn , Choose a teaching style appropriate teach Division, Check online for related information, greatly saves time, Extremely convenient Czech, Flexible, applies to office workers, Education of the subjects of adult education work on . A fact that cannot be ignored is the, Modern information technology and web advances and developments in technology provide technical support for modern distance education, under the lifelong education system , The characteristics of modern distance education pattern conform to social group The requirement of lifelong education for the body, precisely because the lifelong education system was established and the Development, enables modern distance education patterns to reach people 's eyes, and gets a heavy view, can say, Lifelong education system brings development opportunities for modern distance education .

\section{Development challenges}


the establishment and development of a lifelong education system is a model for modern distance education Development and growth offers opportunities, But it also poses the same challenge . in Lifelong education system , A modern remote from modern information technology and network technology process Education with space and time unrestricted, resource-rich and easy to check consult, The advantages of convenient and quick to get people's approval, Modern distance education mode Rapid Development, but, Lifetime education system is still short in China, related Research and practice work is still not perfect, the modern distance developed on this basisthere are also a number of deficiencies in the path education .

(1) Modern distance education is based on network technology and modern information Technology branch

To Develop an educational pattern, in the process , Major Universities Leveraging Network technology and multimedia technology, bring related courses and teaching resources through Network propagation to individuals or groups outside the campus, In the process, student with Teachers do not have face-to-face lectures or conversations, Student's learning status and problems encountered in learning cannot be contacted with the teacher at the first time and get resolved, so , causes a certain delay ; also for teachers, teach problems encountered during the learning process can not be quickly interacted with the students. Stream, so, The information communication lag behind the learning process, for teaching effect a Fixed effect .

(2) For distance education, is bound to go through the computer or some other device

on network pivot, link students to teachers, and Learning Resources material and resources need to be obtained through the network, in this procedure, network Environment the becomes an important link to the quality of modern distance education .. China because of the population base is numerous, with the popularity of the network, China's internet population is rising every year, networks are flooded with groups ofpeople, A network ring formed on this basis Border also affected, Resources in virtual world, knowledge etc True and false , This gives you a lifelong education system to learn about, to Grow your strength, Improve survivability social groups bring no small distress, Although modern remote the content and form of education are not limited to the network, In China, Adult Education's hold, outside Learning Center established by major pilot colleges, Adult self-study all forms, Even if you are using the Internet for Distance education, also has a special network Envelope Address, as in real-world schools, But it is undeniable that, using multimedia technology, Modern distance education such as network technology with the The popularity and rapid development of today's network, increasingly become the core of modern distance education content, More important, so, network environment to modern distance education the effects of are still affected ..

(3) teacher resources are mixed in modern distance education models behavior

Non-specification for network environment management, Modern Distance education course teacher The imperfections of The selection mechanism and the absence of evaluation mechanisms, make some people dasheen number, mixed in real teachers ' team, not only to a certain extent to these the social groups, can also harm their interests .

(4) to establish and develop a lifelong education system in China

in some colleges Line pilot, launch A series of actions, such as adult education, self-study Exams, and other forms , This is a measure to promote the development of lifelong education system, but, our original education spending is lower than world level, in today's adult education Invest Lower, on this basis, Universities in order to ensure modern remote education Bred smoothly. , Combining pursuit of economic benefits with distance education ; Even worse, The interest appeal becomes the first priority for the work of these educational institutions, The pursuit of economic benefits and neglect of distance education to enhance the ability of students Essential Requirements, Lowering quality of education .

three, reform and innovation of modern distance education under the lifelong education system actions

During the establishment and development of a lifelong education system, Enforce distance education Real time and timeliness, Promoting the interaction between students and teachers in the teaching process Move, How 
to standardize the network environment used by modern distance education, Consolidated teachers and teaching resources, is a challenge for modern distance education, Also is an issue that must be addressed for modern distance education to become popular and grow .. on This puts forward countermeasures based on the four points above..

(a) Strengthening communication and interaction between teachers and students in modern distance education

in modern distance education, the mode of teaching through the network is indeed excellent dot Many, But disadvantages are also obvious, Because the real time is not strong, Students learn The course video may be a previous recorded by the teacher in the , or the teacher originally record the teaching video at a specified time , And the students are wrong for a variety of reasons best time to watch video, so, causes students ' learning and teachers ' teachings Time difference, from, Teacher-student interaction issues are also affected One of the important reasons for teaching effects . and currently, with economic development , "" "" The booming live industry is now Prairie fire, Live playback of the main broadcast behavior, language and so on, has real time , Large Traffic, ac

Strong, Space-time limitation small, Low Cost, audience Wide, set up an education live flat console enables live classroom online video interaction, Discussion, debate, etc. features, as a private training institution, in the course of the launch, , including webcast course, Students who purchase this course, No need to accept face-to-face teaching on site, and is available through the network, viewing teacher lectures on a computer, If a student encounters a problem in the course of granting, to communicate with the teacher through the play screen . -The Benefits of a comprehensive distance education platform at the same time, can be very large to address the problem of real-time communication between teachers and students in distance education . because this, under the National establishment and improvement of lifelong education system requirements, will live industry with The combination of distance education is the effective way to solve the existing distance education students and teachers Exchange problems .

(b) Purify Network, Create a good learning environment

Network Education is the construction of lifelong education system in the new generation of adult learning adult , Important ways for people to continue their studies . network environment to modern far The impact of the education is mainly reflected in the unusually large flow of information, resulting all kinds of incomplete wrong information flooded in virtual world, Obvious example, on is a severe period of avian influenza, NET-pass salt has effect on avian influenza, and it's causing people everywhere to hoard salt. . of course in distance education generally have their own web site or a dedicated virtual Web site, The education process is in these virtual on the proposed web site, as set up by pilot schools, Education Training agencies also have special sites . But students in distance education are as old as the the long adult group ,in particular social groups with relatively low educational attainment body, bombing web environment information, will undoubtedly be affected, Especially in the process of finding data and learning resources on the network, not only has to get the wrong message , worse, will suffer from network scams . so , to Purify network environment ,Spec Network admin, establish a strong and reasoned penalty mechanism, Strictly verify the behavior of spreading false information and network fraud and admin, Create a good external learning environment for distance education .

(c) Establish a sound teacher certification and evaluation mechanism

in the course of modern distance education, School and private education training Teacher resources in general should have higher professional qualities and knowledgeskill level, but in reality, Distance Education teachers ' team resources exist well " atrazine " , Modern distance education of network technology and multimedia technology at the same time for for people with convenience, also increases the uncertainty of the teaching process, This inaccuracy qualitative is embodied both in the student side, also reflected in the teachers ' team . network environment Administrative vulnerabilities, makes it possible for the distance education faculty to 
mix impostors generation ,This part of the person does not have strong professionalism and knowledge skills , naturally also will not meet students ' learning needs. Former teacher is considered a rice bowl One job , If you have a teacher certificate, can always be the teacher's identity work, and with the development of the Times, The state has also proposed a corresponding reform in this respect Read, the teacher who has obtained the teacher's qualification certificate should also Accept Accreditation Exams, If you cannot pass this exam, can no longer be taught Division . should also be so in distance education, developing strict teacher authentication mechanism, On the one hand, qualification test for teachers who have participated in distance education, tick Except teachers not meeting the requirements, Excellence ; On the other hand, To participate far teacher qualification in Process education, filter out professional quality, know all Skills Complete, teaching excellent teachers with rich experience ; at the same time, in distance education , also establish and refine teacher evaluation mechanisms , The part of the evaluation is mainly from the learning the The student finds the , The teacher satisfaction survey for students receiving distance education, Make adjustments to teachers engaged in distance education according to the findings . measures to establish a teacher accreditation and evaluation Mechanism, Private Education Training machine refactoring is equally important, total, Make sure the teachers in modern distance education Quality, to improve the teaching quality of modern distance education, really make students knowledge, skills and survivability are promoted .

(d) Public , Deep cooperation between private educational institutions

in the course of modern distance education, Excessive economic benefits in some institutions Pursuit leads to neglect of teaching quality, significantly affect accepting modern distance educators Group learning effects, but due to the country's low investment in education, schools for Modern Distance education, and not enough money, nature to charge a certain cost, at this point, can be tightened public, The two private education institutions cooperation, Public colleges and universities have sufficient teaching resources and truly qualified teaching teachers ; While private education institutions have some advantages in specialized skills training potential, More importantly, The management mechanism of public institutions is relative to private education Organization more specification and Perfection, launch Public, The deep cooperation of the private two educational institutions, is the advantage of combining two major institutions, Overcoming the respective disadvantages of teaching Parenting mode . on the one hand, standardize management of modern distance education, Rationalization , reduce excessive pursuit of economic benefits , to ignore the quality of teaching condition occurrence ; On the other hand, fully leverage both sides of the resource, is advantageous for adding Strong teaching quality, guaranteed teaching effect .

\section{Reference}

1. Ong Juhua . Integral re-construction of lifelong education system -- Japanese Learning three people talk J . Open Education Research , (5) : 4-15.

2. Zi, Shangguo . An analysis of the architecture of lifelong education J . China remote Education, (one) : - 34 .

3. King star . A strategic study of the construction of lifelong education system with Chinese characteristics [D]]. Taiyuan : Master's degree thesis of Shanxi University, 013.

4. Li dynasty have, yellow floret. , A comparative study of the current development of modern distance education investigate -- Phoenix University of the United States and the modern distance of Tsinghua College in China Process Education Example J]. Continuing Education Research , (1) : -81.

5. da lang. . integrated development of modern distance education and traditional adult education Research D]. Xi ' an : Shaanxi Normal University master's degree thesis , 2013. 